\title{
Addiction and the Utilization of Medical Care
}

\author{
Yen-Ju Lin, ${ }^{1}$ Chun-Chih Chen, ${ }^{2}$ Tsai-Ching Liu, ${ }^{3}$ and Ying-Tzu Lin ${ }^{4}$ \\ ${ }^{1}$ Department of Public Finance and Taxation, National Taichung Institute of Technology, 129 Section 3, San-Min Road, \\ Taichung 404, Taiwan \\ ${ }^{2}$ Department of Economics, National Taipei University, 151, University Road, San Shia, New Taipei City 23741, Taiwan \\ ${ }^{3}$ Department of Public Finance, National Taipei University, 151, University Road, San Shia, New Taipei City 23741, Taiwan \\ ${ }^{4}$ Institute of Human Resource Management, National Sun Yat-Sen University, 70, Lienhai Road, Kaohsiung 80424, Taiwan
}

Correspondence should be addressed to Tsai-Ching Liu, tching@mail.ntpu.edu.tw

Received 25 July 2011; Revised 9 September 2011; Accepted 13 September 2011

Academic Editor: David E. Giles

Copyright (๑) 2012 Yen-Ju Lin et al. This is an open access article distributed under the Creative Commons Attribution License, which permits unrestricted use, distribution, and reproduction in any medium, provided the original work is properly cited.

\begin{abstract}
We investigate the effect of different scales of addictive factors on the utilization of medical services in this paper using a two-part model. Data are from the 2005 National Health Interview Survey and the claims data in the National Health Insurance Research Database in Taiwan. The results show that personal addictive behavior is significantly associated with both outpatient and inpatient utilization. Moreover, our result implies that those who smoked at least 20 cigarettes per day might not visit a doctor until the illness was severe. It suggests that the government can accomplish these goals by promotion and education in order to increase public awareness of personal health.
\end{abstract}

\section{Introduction}

In order to provide extensive medical care, Taiwan has since 1995 implemented a national health insurance system that has increased the accessibility to medical care and alleviated the personal financial burden in relation to medical expenses. On the other hand, the national medical care expenditure in Taiwan has increased year by year owing to the prolonged life expectancy and the prevalence of chronic diseases resulting from changes in lifestyle [1-6]. The ever-increasing medical expenditure has become a worldwide problem although the health insurance system differs across nations. Many researchers have examined possible causes of the increase in expenditure in order to design a system that keeps medical expenditure under control $[1,4-11]$.

Previous studies indicate that personal health status and medical expenditure are associated with modifiable risk factors [12-19]. For example, some unhealthy behaviors, such as smoking, excessive drinking, chewing betel nut, lack of exercise, and an unbalanced diet, have been identified as the major causes of several chronic diseases. The increase in chronic disease morbidity directly raises the national medical expenditure and aggravates the family's financial burden $[14,20-25]$.
Smoking, drinking, and chewing betel nut have been proven to jeopardize personal health. Some medical research shows that smoking leads to lung cancer, laryngeal cancer, asthma, and cardiovascular diseases [16, 17, 26-29]. Compared to those who do not smoke, smokers have shorter life expectancy and incur higher medical expenditure [14, $16,19,29,30]$, and the people who are affected by secondhand smoke also tend to incur higher medical expenditure $[25,31]$. Moreover, although appropriate drinking does no harm personal health [32-35], excessive drinking increases the numbers of accidents and the morbidity of liver cancer. Furthermore, chewing betel nut has been related to oral diseases such as oral cancer, oral submucous fibrosis, and oral leukoplakia. Over $60 \%$ of oral cancer patients habitually chew betel nuts and oral cancer is one of the major causes of death in Taiwan $[36,37]$. It is difficult to break the habits of smoking, drinking, or chewing betel nut, in general, those unhealthy behaviors have been regarded as addictive. Since these addictive factors lead to chronic diseases that further increase the national medical expenditure, it is important for the policymakers to effectively lower the prevalence of these addictive factors.

In Taiwan, there is an upward trend in tobacco control. To improve the nation's health, the Tobacco Hazards Control 
Act has been implemented since September 1997. Moreover, a health and welfare surcharge has been applied to tobacco products since 2002. The surcharge was NTD 5 per pack of cigarettes in the beginning and was raised to NTD 10 per pack in 2006. Some $90 \%$ of the surcharge is used as funding for the National Health Insurance and the remaining 10\% of it is used to control tobacco use, the promotion of health, illegal tobacco investigations, surcharge evasion prevention, and social welfare [38]. Moreover, the government implemented the revised Tobacco Hazards Control Act on January 11, 2009 to designate more public places as no smoking areas. Furthermore, the health and welfare surcharge was raised to NTD 20 per pack of cigarettes in June 2009 [38]. Furthermore, the government promotes the Tobacco Hazards Control Act through the media, including through television, the Internet, and broadcasting, and provides a 24-hour complaint hotline. In addition, the government establishes various means, such as community classes, hospital classes, and hotlines to help the smokers break the habit of smoking. The government expects to reduce the prevalence of smoking and to provide more smoke-free environments through these controls and promotions [38].

According to statistics compiled by the Department of Health [39], the ratios of smoking males and females in the 1980 s were $60.4 \%$ and $3.4 \%$, respectively. The ratios became $48.2 \%$ and $5.3 \%$ in 2002 and $38.6 \%$ and $4.8 \%$ in 2008. This shows that the tobacco control policy reduced the proportion of smoking males significantly. Although the ratio of smoking females did not decline, it did not increase significantly, either ${ }^{1}$.

A great number of studies have investigated the effect of smoking, drinking, and chewing betel nut on medical utilization and expenditure. Most of them conclude that these addictive behaviors jeopardize personal health and aggravate the medical expenditure burden [12-19, 33-37]. However, some research limitations still exist, such as the lack of a nationwide dataset or a scale of addictive behavior. For example, Lin [13] analyzes the relationship between the modifiable health risk factors and medical care use and expenditure in Taiwan, linking the 2001 National Health Interview Survey (NHIS) and the claims data in the National Health Insurance Research Database (NHIRD) in Taiwan. Although the dataset is nationwide in terms of its scope, the study does not examine the effect of different scale of the risk factors on medical utilization. For instance, Lin [13] regarded the unhealthy drinking factor as "whether or not the respondent drinks everyday." However, moderate regular drinking may have a positive effect on health and risky for illness, injury, and death arising from alcohol misuse [33]. Therefore, "mild" unhealthy behaviors may have little effect on health. In order to analyze the effect of immoderate unhealthy behavior on health, we define addictive behaviors more carefully.

This study also contributes to the literature in the way that we investigate the effect of different scales of the addictive behavior on medical service utilization. The addictive scale is assigned a value of one or two if a person has one or two addictive behaviors. For representativeness, we combine two nationwide data sets: the 2005 National
Health Interview Survey (NHIS) and the claims data in the National Health Insurance Research Database (NHIRD). We believe that our analysis can provide useful information for the health policymaking process.

\section{Methods}

2.1. Database and Study Sample. There are two sources of data in this study. The first dataset is the 2005 National Health Interview Survey (NHIS) conducted by the National Health Research Institutes (NHRI) and the Bureau of Health Promotion (BHP) in Taiwan. The dataset is based on multistage stratified systematic sampling design and contains all 23 counties and cities in Taiwan. The data were collected by faceto-face interviews between April and August 2005. There were 30680 interviewees and 24726 of them completed the interview (completion rate $=80.59 \%$ ). There were three kinds of questionnaires for three age groups: below 12, 1264 , and above 65 . The numbers of completed interviews for the three age groups were 3900,18099 , and 2727 , respectively.

The questionnaire contained various aspects of the interviewees' information. First, personal socioeconomic variables included age, sex, race, education, marital status, and geographical location. Second, personal health status and behavioral variables included disease history, eating behavior, living style, height, and weight. Last, the data also provided information regarding personal medical service utilization, self-awareness of health status, and economic status such as occupation and income.

The second data source is the 2005 National Health Insurance Research Database (NHIRD). The merit of the dataset is its completeness since it contains all medical utilization records under National Health Insurance. However, the shortcoming of the dataset is that it lacks other aspects of personal information such as socio-economic status. In order to link the personal socio-economic status with the personal medical utilization records, the NHRI combines the 2005 NHIS dataset and NHIRD based on the agreement of interviewees. 18538 out of 24726 completed interviewees were willing to provide their personal information for research. 15574 out of 18538 volunteers were aged 12 and above, and 2,964 consisted of those below the age of 12 . Generally speaking, medical services are in high demand among the elderly and children. The inclusion of these groups may lead to estimation bias. To avoid such bias, we choose interviewees between the ages of 12 and 64 in our analysis.

Our explained variables are the utilizations of the outpatient and inpatient services from the second dataset (2005 NHIRD). One advantage of using NHIRD is accuracy since the NHIRD contains each record of personal medical utilization under the national health insurance and we can avoid potential memory bias from usual survey data. The explanatory variables of interest are the degrees of addiction to smoking, drinking, and chewing betel nut obtained from the first dataset (2005 NHIS). The 2005 NHIS questionnaire contained the questions relating to history of smoking, 
drinking, and chewing betel nut applying face-to-face interviews. In addition, the information about personal socioeconomic status, health status, and geographical location was also included in the questionnaire. In the following analysis, we control for these variables to analyze the effect of addictive behaviors on medical utilization.

We provide some questions regarding unhealthy behaviors contained in the 2005 NHIS questionnaire. The respondents were asked, "Do you drink currently?" For those who answered "yes," they were asked "How often do you drink?" and "Do you get drunk?" We regard an individual as a drinker if he/she gets drunk at least once a week. For smoking, the respondents were asked, "Have you ever smoked?" For those who answered "yes," they were asked "Have you ever smoked during the past month?" and "How many cigarettes do you smoke a day?" We regard an individual as a smoker if he smoked at least 20 cigarettes per day during the past month. For chewing betel nut, the respondents were asked, "Have you ever chewed betel nut?" For those who answered "yes," they were asked, "Have you ever chewed during the past six months?" and "How often do you chew during the past six months?" We regard an individual as a betel nut chewer if he chews betel nut at least 1-2 days a week.

In order to reduce the response bias, we delete the observations containing answers such as "forget," "do not know," or "refuse to answer." We also delete the observations with missing values and there are 13651 effective samples out of 15574 original observation (response rate $=87.65 \%$ ). Moreover, there are only 6 observations that have all three addictive factors and none of them used inpatient services in 2005, which leads to estimation difficulties. Therefore, we only use 13645 observations and analyze the different addictive behaviors by grouping them into one addictive factor or two addictive factor groups.

2.2. Statistical Analysis and Variables of Interest. In general, people do not decide whether to use medical services and decide the number of the services at the same time. It is more likely that people decide whether to use medical service first and then decide the frequency of medical utilization once they receive medical service [40]. Therefore, the twopart model is appropriate in our application. Since the numbers of outpatient and inpatient visits are count data, we consider the Poisson regression and the Negative Binomial regression in the second part of our analysis. The feature of overdispersion (the variance usually exceeds the mean) usually exhibits in count data. We apply the overdispersion test described in Cameron and Trivedi [41], and the result strongly rejects the null that the overdispersion parameter is zero. It implies that the data are overdispersed and the Negative Binomial distribution is more appropriate in our application.

Two common models are used to deal with the phenomenon of excess zeros in count data. In addition to the two-part model, the zero-inflated models, such as zeroinflated Poisson (ZIP) and zero-negative binomial (ZINB), are also capable of excess zeros and also popular in the literature. Some studies have compared the two-part model (hurdle model) and the zero-inflated model and details about the debates can be found in Jones [42]. In this study, we choose the model based on information criteria. We compare three models, Negative Binomial Hurdle, Zeroinflated Poisson, and Zero-inflated negative binomial (NBH, ZIP, and ZINB), using two information criteria, AIC and BIC. Both criteria suggest ZIP performs worse than NBH and ZINB. This result is not surprising since the equidispersion assumption of Poisson distribution is too restrictive in most empirical applications. The comparison results for $\mathrm{NBH}$ and ZINB are mixed. Both criteria prefer NBH for unadjusted, specification in 3 out of 4 cases-unadjusted outpatient utilizations, unadjusted and adjusted inpatient utilizations; both criteria select ZINB only for adjusted outpatient case. However, the performance difference between NBH and ZINB is small from both criteria. Moreover, the estimation results from both models are similar qualitatively. For consistent presentation, we choose $\mathrm{NBH}$ in the following analysis.

In addition to information criteria, Pohlmeier and Ulrich [40] provide specification tests to determine whether their two-part model is adequate. However, their method cannot be directly applied to our work. In order to perform the specification tests, they assume the underlying distribution for both parts is Negbin 1 so that all models in comparison are nested. The two-part model we used is the logit-Negbin 2 , which is more flexible and is commonly used in health utilization literature $[42,43]$.

Our two-part model can be described as the following form [41]:

$$
g(y)= \begin{cases}f_{1}(0) & \text { if } y=0 \\ \frac{1-f_{1}(0)}{1-f_{2}(0)} f_{2}(y) & \text { if } y \geq 1 .\end{cases}
$$

Following Häkkinen et al. [43] and Gerdtham [44], we specify logistic density in the first part, $f_{1}(\cdot)$, and negative binomial density in the second part, $f_{2}(\cdot)$. In the first part, we study the effect of personal addictive behavior on whether or not people utilize outpatient services or inpatient services. In the second part, we examine the people who used medical services in the year 2005 and analyze the personal addictive behavior effecting the frequency of outpatient services $(N=$ $12,468)$ and inpatient services $(N=873)$.

We divide the medical utilization into outpatient services and inpatient services. The explained variables for outpatient services include whether the respondent used outpatient care services and the number of outpatient visits. The dependent variables for inpatient services are whether the respondent used inpatient care services and the number of inpatient services $^{2}$.

The independent variables of interest are three individual addictive dummy variables and three cross addictive dummy variables. "Drunk (DD)" equals one if the respondent drinks at least once a week and gets drunk; "Smoking (SM)" equals one if the respondent smokes at least 20 cigarettes every day during the past month; "Chewing betel nut (CBN)" equals 
one if the respondent chews betel nut at least 1-2 days a week. Moreover, we consider the relationship between the degree of addictive behavior and medical service utilization that has not been studied in previous research. A high degree of addictive behavior means that the respondent has two addictive factors (DD $+\mathrm{SM}, \mathrm{DD}+\mathrm{CBN}$, and $\mathrm{SM}+\mathrm{CBN}$ ) at the same time.

The other control variables include the personal socioeconomic variables, health status variables, and geographical variables. The socioeconomic variables include gender, age, marital status, education, and monthly income. The health status variables consist of the BMI and the disease history where the respondent has had heart disease, hypertension, diabetes, cholesterol, or strokes in the past. The geographical variables show the residential location of the respondent: northern, central, southern, and eastern. Table 1 shows the definition of all variables in detail. The descriptive statistics are shown in Tables 2 and 3. Tables 4 and 5 present the estimation results for outpatient and inpatient services, respectively. The difference between Model 1 (unadjusted) and Model 2 (fully adjusted) is that the former includes only the six key variables of interest but the latter includes the other control variables, such as the socio-economic, health status, and geographical variables.

\section{Results}

3.1. Descriptive Statics. Table 2 shows the characteristics of our sample. There are 627 people who are drunk at least once per week (DD), 457 individuals who smoke at least 20 cigarettes every day during the past month (SM), 979 people who chew betel nuts at least 1-2 days per week (CBN), and 11,885 persons (about $87 \%$ of the sample) who have none of the addictive factors. The sum of these four numbers is greater than the number of all persons $(13,948>13,645)$ because the addictive factors are not mutually exclusivethe people may have more than one addictive factor. Around $52 \%$ of the respondents are male, and most of the people with addictive factors are male. The average age of the study sample is 35.84 . The $21-35$ age group is the majority group which consists of about one-third of our sample. More than one-half $(52.44 \%)$ of those in the sample are married. The average number of years of education is 11.06, and about one-third of the sample $(33.36 \%)$ have a senior high school degree as their highest degree achieved. We divide the sample into 5 income groups, and nearly $30 \%$ of our sample have a monthly income that falls within the range of 20,000-39,999 New Taiwan dollars (NTD). However, the observations with a monthly income of NTD 60,000 and above account for only $7.11 \%$ of our sample.

As for the health status variables, the average BMI is 23.04. From the aspect of disease history, $10.52 \%$ of the sample have high cholesterol; $7.99 \%$ of the sample have hypertension; $3.22 \%$ of the sample have heart disease; and 3.09 of the sample have diabetes. Only $0.46 \%$ of the sample have experienced a stroke. As regards the geographical variables, the residential locations are categorized into four groups: northern, central, southern, and eastern. Most of the sample observations $(48.03 \%)$ are from the north and the least $(7.16 \%)$ are from the east. Geographically, the sample distribution is close to the population distribution in Taiwan.

Table 3 shows that $91.37 \%$ of our respondents used outpatient services at least once and the average number of outpatient visits is 14.19 . By contrast, only $6.4 \%$ of our overall sample used inpatient services at least once and the average number of inpatient visits is 1.48. In addition, if the respondent smokes at least 20 cigarettes every day, the probability that he uses outpatient services is higher than that of other groups regardless of whether he has another addictive factor or not. If the respondent smokes at least 20 cigarettes every day, the average number of outpatient visits is also higher than that of other groups. Furthermore, once the individual who smokes at least 20 cigarettes every day uses inpatient services, the average number of visits is higher than that of other groups.

3.2. Regression Models. Table 4 presents the estimation results of the effect of addictive factors on outpatient service utilization. Model 1 (the unadjusted model) includes only the six key variables of interest, and Model 2 (the fully adjusted model) also controls for socio-economic, health status, and geographical variables. We do not report the estimation results for these control variables because we are interested in the six addictive variables. Table 4(a) shows the results from the first part logit regression. Table 4(b) shows the results from the second part of Negative Binomial model, analyzing the frequency of outpatient services. Both models indicate that the probability of using outpatient services is lower for a person who has DD, CBN, or both addictive factors $(\mathrm{DD}+\mathrm{CBN})$ than for a person without any addictive factors. Once a person with $\mathrm{DD}, \mathrm{CBN}$, or DD+CBN uses outpatient services, they utilize the outpatient services less frequently than those without any addictive factors. By contrast, if a person has SM alone, the probability of using outpatient services is not significantly different from that for a person without any addictive factors using them. However, once he visits a doctor, the number of visits is significantly higher than that of a person without addictive factors.

Table 5 presents the estimation results of the effect of addictive factors on inpatient service utilization and leads to different implications. Both models in Table 5(a) indicate that the probability of using inpatient services for the DD and for the SM is significantly greater than that for the nonaddictive factor group. Moreover, Table 5(b) shows that once the SM group uses inpatient services, the frequency of medical services is highly significantly greater than those of the non-addictive factor group. For the DD group, the probability of using inpatient services is higher than that for the non-addictive factor group while the frequency of inpatient services is not significantly different from that of the base group. From Table 3, we see that the numbers of inpatient observations in the two-addictive-factor groups are small. For example, there is only one observation in the $\mathrm{SM}+\mathrm{CBN}$ group. In order to obtain more reliable inferences, we combine these three two-addictive factor groups into one group in Table 5. We do not find the evidence of higher probability or frequency of inpatient service utilization for the two-addictive-factor group. 
TABLe 1: Definitions of dependent and independent variables.

\begin{tabular}{|c|c|}
\hline Variable & Definition \\
\hline \multicolumn{2}{|l|}{ Dependent variables } \\
\hline Outpatient services & Dummy variable $=1$ if respondent received outpatient care, otherwise $=0$ \\
\hline Number of outpatient services & The number of times outpatient care received per respondent \\
\hline Inpatient services & Dummy variable $=1$ if respondent received inpatient care, otherwise $=0$ \\
\hline Number of inpatient services & The number of times inpatient care received per respondent \\
\hline \multicolumn{2}{|l|}{ Independent variables } \\
\hline \multicolumn{2}{|l|}{ Additive Factor } \\
\hline $\begin{array}{l}\text { Drinking every week and deep } \\
\text { drunk }\end{array}$ & Dummy variable $=1$ if respondent drinks every week and gets drunk, otherwise $=0$ \\
\hline Former smoker & Dummy variable $=1$ if respondent smokes at least 20 cigarettes every day, otherwise $=0$ \\
\hline Chewing betel nut & Dummy variable $=1$ if respondent chews betel nut at least one or two days per week, otherwise $=0$ \\
\hline No addictive factors & Dummy variable $=1$ if respondent is without addictive factors, otherwise $=0$ \\
\hline \multicolumn{2}{|l|}{ Socio-demographic variables } \\
\hline Male & Dummy variable $=1$ if respondent is male, otherwise $=0$ \\
\hline \multicolumn{2}{|r|}{ 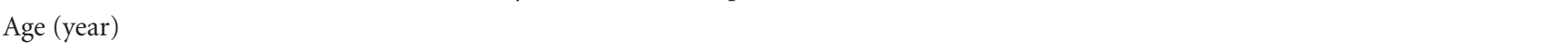 } \\
\hline $12-20$ & (Respondent's age in this range is the reference category) \\
\hline $21-35$ & Dummy variable $=1$ if respondent's age is in this range, otherwise $=0$ \\
\hline $36-50$ & Dummy variable $=1$ if respondent's age is in this range, otherwise $=0$ \\
\hline $51-64$ & Dummy variable $=1$ if respondent's age is in this range, otherwise $=0$ \\
\hline Married & Dummy variable $=1$ if respondent has married, otherwise $=0$ \\
\hline \multicolumn{2}{|l|}{ Education level } \\
\hline Primary school and below & Dummy variable $=1$ if respondent finished primary school and below, otherwise $=0$ \\
\hline Junior high & Dummy variable $=1$ if respondent finished junior high school, otherwise $=0$ \\
\hline Senior high & Dummy variable $=1$ if respondent finished senior high school, otherwise $=0$ \\
\hline College and above & (College and above is the reference category) \\
\hline \multicolumn{2}{|l|}{ Individual monthly income } \\
\hline NT \$ 0 & Dummy variable $=1$ if individual's monthly income is in this range, otherwise $=0$ \\
\hline NT \$ 1-19,999 & Dummy variable $=1$ if individual's monthly income is in this range, otherwise $=0$ \\
\hline NT \$20,000-39,999 & Dummy variable $=1$ if individual's monthly income is in this range, otherwise $=0$ \\
\hline NT \$ 40,000-59,999 & Dummy variable $=1$ if individual's monthly income is in this range, otherwise $=0$ \\
\hline NT $\$ \geq 60,000$ & (Individual's monthly income in this range is the reference category) \\
\hline \multicolumn{2}{|l|}{ Health status } \\
\hline BMI & The number of respondent's body mass index (BMI) \\
\hline Heart disease & Dummy variable $=1$ if respondent has heart disease, otherwise $=0$ \\
\hline Hypertension & Dummy variable $=1$ if respondent has hypertension, otherwise $=0$ \\
\hline Diabetes & Dummy variable $=1$ if respondent has diabetes, otherwise $=0$ \\
\hline Cholesterol & Dummy variable $=1$ if respondent has cholesterol, otherwise $=0$ \\
\hline Stroke & Dummy variable $=1$ if respondent has stroke, otherwise $=0$ \\
\hline \multicolumn{2}{|l|}{ Geographical variables } \\
\hline \multicolumn{2}{|l|}{ Residential locations } \\
\hline Northern & $\begin{array}{l}\text { Dummy variable }=1 \text { if the household is located in Taipei Hsien, Keelung City, Ilan Hsien, Taoyuan } \\
\text { Hsien, Hsinchu Hsien, Miaoli Hsien, and Taipei Municipality (north is the reference category) }\end{array}$ \\
\hline Central & $\begin{array}{l}\text { Dummy variable }=1 \text { if the household is located in Taichung Hsien, Changhua Hsien, Nantou Hsien, } \\
\text { Yunlin Hsien, and Taichung City }\end{array}$ \\
\hline Southern & $\begin{array}{l}\text { Dummy variable }=1 \text { if the household is located in Chiayi Hsien, Tainan Hsien, Kaohsiung Hsien, } \\
\text { Pingtung Hsien, Kaohsiung Municipality, Chiayi City, and Tainan City }\end{array}$ \\
\hline Eastern & Dummy variable = 1 if the household is located in Taitung Hsien, Hualien Hsien, Penghu Hsien \\
\hline
\end{tabular}


TABLE 2: Characteristics of the study sample.

\begin{tabular}{|c|c|c|c|c|c|}
\hline & All persons & Persons with DD & Persons with SM & Persons with CBN & $\begin{array}{c}\text { No } \\
\text { addictive } \\
\text { factors }\end{array}$ \\
\hline$\%^{\mathrm{a}}$ (Total no. $)$ & $100(13,645)$ & $4.60(627)$ & $3.35(457)$ & $7.17(979)$ & $87.06(11,885)$ \\
\hline \multicolumn{6}{|l|}{ Socio-demographic variables } \\
\hline Male & 51.95 & 89.63 & 91.25 & 91.83 & 46.19 \\
\hline Age (Years) & 35.84 & 40.33 & 45.09 & 39.87 & 35.03 \\
\hline $12-20$ & 17.10 & 1.59 & 2.63 & 2.45 & 19.27 \\
\hline $21-35$ & 33.28 & 34.93 & 19.47 & 34.53 & 33.65 \\
\hline $36-50$ & 31.20 & 43.86 & 40.48 & 46.68 & 29.33 \\
\hline $51-64$ & 18.42 & 19.62 & 37.42 & 16.34 & 17.75 \\
\hline Married & 52.44 & 58.37 & 74.84 & 64.35 & 50.53 \\
\hline Education Years & 11.06 & 10.23 & 11.32 & 9.65 & 11.17 \\
\hline Primary school and below & 16.18 & 18.02 & 16.19 & 20.02 & 15.90 \\
\hline Junior High & 19.90 & 30.14 & 19.26 & 33.71 & 18.59 \\
\hline Senior High & 33.36 & 35.73 & 33.04 & 39.02 & 32.86 \\
\hline College and above & 30.56 & 16.11 & 31.51 & 7.25 & 32.65 \\
\hline \multicolumn{6}{|l|}{ Individual monthly income } \\
\hline NT \$ 0 & 26.40 & 6.86 & 13.57 & 7.86 & 28.93 \\
\hline NT \$ 1-19,999 & 23.85 & 21.85 & 19.69 & 25.94 & 23.97 \\
\hline NT \$20,000-39,999 & 29.57 & 35.41 & 28.45 & 39.33 & 28.64 \\
\hline NT \$ 40,000-59,999 & 13.07 & 21.37 & 19.04 & 19.31 & 12.15 \\
\hline NT $\$ \geq 60,000$ & 7.11 & 14.51 & 19.25 & 7.56 & 6.31 \\
\hline \multicolumn{6}{|l|}{ Health status } \\
\hline$B M I$ & 23.04 & 24.39 & 24.35 & 24.93 & 22.80 \\
\hline Heart disease & 3.22 & 2.07 & 7.22 & 3.68 & 3.10 \\
\hline Hypertension & 7.99 & 12.60 & 15.97 & 10.32 & 7.35 \\
\hline Diabetes & 3.09 & 3.99 & 7.22 & 5.72 & 2.73 \\
\hline Cholesterol & 10.52 & 13.72 & 21.01 & 12.26 & 9.84 \\
\hline Stroke & 0.46 & 0.80 & 2.41 & 0.72 & 0.35 \\
\hline \multicolumn{6}{|l|}{ Geographic variables } \\
\hline \multicolumn{6}{|l|}{ Residential locations } \\
\hline North & 48.03 & 46.73 & 48.36 & 33.71 & 49.00 \\
\hline Center & 20.96 & 16.59 & 23.63 & 22.47 & 20.88 \\
\hline South & 23.85 & 22.33 & 22.76 & 28.40 & 23.65 \\
\hline East & 7.16 & 14.35 & 5.25 & 15.42 & 6.47 \\
\hline
\end{tabular}

DD: deep drunk; SM: smoking cigarettes; CBN: chewing betel nut.

a The rows add up to $>100 \%$ because some individuals had multiple addictive factors.

\section{Discussion}

This study investigates the effect of three addictive factors on medical service utilization in terms of probability and frequency. Our dataset is combined from the 2005 NHIS and the NHRID in Taiwan so that we have both personal records of medical utilization and personal socio-economic variables. We use the hurdle model with the logit model in the first part and the negative binomial model in the second part. We also control for personal socio-economic, health, and geographical variables. We contribute to the literature in that we analyze not only the effect of individual addictive factors, but also the effect of combined addictive factors.

Our empirical results show that personal addictive behavior is significantly associated with both outpatient and inpatient utilization. Compared to those without any addictive factors, a person in the DD group (who gets drunk at least once per week and has no other addictive factors) has lower outpatient utilization likelihood in the first part and visits a doctor less frequently in the second-part analysis. However, the people in the DD group have the highest odds ratio in the inpatient analysis from Model 2 (in Table 5), indicating they are most likely to use inpatient services 
TABLE 3: Health care utilization by addictive factor classification.

\begin{tabular}{|c|c|c|c|c|c|c|c|c|}
\hline & Total & DD alone & SM alone & CBN alone & $\mathrm{DD}$ and $\mathrm{SM}$ & $\mathrm{DD}$ and $\mathrm{CBN}$ & SM and CBN & $\begin{array}{l}\text { No addictive } \\
\text { factors }\end{array}$ \\
\hline Total no. & 13645 & 343 & 412 & 702 & 26 & 258 & 19 & 11885 \\
\hline \multicolumn{9}{|l|}{ Outpatient } \\
\hline Total no. & 12468 & 294 & 378 & 586 & 25 & 205 & 18 & 10962 \\
\hline Proportion $^{\mathrm{a}}(\%)$ & 91.37 & 85.71 & 91.75 & 83.48 & 96.15 & 79.46 & 94.74 & 92.23 \\
\hline Number of visits & 14.19 & 11.89 & 20.52 & 13.06 & 15.52 & 10.90 & 16.44 & 14.14 \\
\hline \multicolumn{9}{|l|}{ Inpatient } \\
\hline Total no. & 873 & 34 & 44 & 54 & 4 & 18 & 1 & 718 \\
\hline Proportion ${ }^{\mathrm{b}}(\%)$ & 6.40 & 9.91 & 10.68 & 7.69 & 15.38 & 6.98 & 5.26 & 6.04 \\
\hline Number of visits & 1.48 & 1.38 & 2.39 & 1.37 & 2.25 & 1.22 & 4 & 1.44 \\
\hline
\end{tabular}

DD: deep drunk; SM: smoking cigarettes; CBN: chewing betel nut.

a The probability of individuals with outpatient services.

${ }^{\mathrm{b}}$ The probability of individuals with inpatient services.

TABLE 4: Estimation results of addictive factors on outpatient service utilization.

(a) Likelihood of outpatient services $(N=13,645)$

\begin{tabular}{lcccc}
\hline & \multicolumn{2}{c}{ Model 1 $^{\mathrm{a}}$} & & Model 2 $^{\mathrm{b}}$ \\
& Odds ratio & Standard error & Odds ratio & $0.743^{+}$ \\
DD & $0.505^{* * *}$ & 0.080 & 1.125 & 0.211 \\
SM & 0.936 & 0.171 & $0.635^{* * *}$ & 0.074 \\
CBN & $0.425^{* * *}$ & 0.046 & 3.078 & 3.158 \\
DD + SM & 2.105 & 2.148 & $0.500^{* * *}$ & 0.083 \\
DD + CBN & $0.326^{* * *}$ & 0.051 & 2.069 & 2.139 \\
SM + CBN & 1.516 & 1.558 & Reference category \\
No addictive factors & \multicolumn{2}{c}{ Reference category } \\
\hline
\end{tabular}

(b) Frequency of outpatient visits $(N=12,468)$

\begin{tabular}{lcccc}
\hline & \multicolumn{2}{c}{ Model 1 $^{\mathrm{a}}$} & & Model 2 $^{\mathrm{b}}$ \\
& Coefficient & Standard error & Coefficient & Standard error \\
\hline $\mathrm{DD}$ & $-0.187^{* *}$ & 0.060 & $-0.141^{* * *}$ & 0.055 \\
$\mathrm{SM}$ & $0.393^{* * *}$ & 0.052 & $0.310^{* * *}$ & 0.047 \\
$\mathrm{CBN}$ & $-0.086^{*}$ & 0.043 & $-0.074^{+}$ & 0.040 \\
$\mathrm{DD}+\mathrm{SM}$ & 0.099 & 0.200 & 0.045 & 0.180 \\
$\mathrm{DD}+\mathrm{CBN}$ & $-0.281^{* * *}$ & 0.072 & $-0.308^{* * *}$ & 0.066 \\
SM + CBN & 0.160 & 0.235 & 0.049 & 0.211 \\
No addictive factors & \multicolumn{2}{c}{ Reference category } \\
\hline
\end{tabular}

DD: deep drunk; SM: smoking cigarettes; CBN: chewing betel nut.

$* * * P<0.001, * * P<0.01, * P<0.05,{ }^{+} P<0.1$

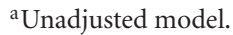

${ }^{\mathrm{b}}$ Fully adjusted model controlling for socio-demographic, health status, and geographical factors.

(1.87 times of the base group people). This may imply that the people in the DD group usually overlook personal health: they do not visit a doctor until the illness is severe. Therefore, it is inevitable for the government to advise people to avoid excessive drinking.

For the respondent in the SM group (smoking at least 20 cigarettes every day and has no other addictive factors), the frequency of outpatient visits is higher, although the probability of using outpatient services is not significantly different from that of those respondents in the base group.
For the inpatient services, the people in the SM group have higher probability to be hospitalized than those in the base group (1.722 times of odds in Model 2, Table 5(a)). Moreover, the people in the SM group also use inpatient services more frequently than those in the base group-the difference in the logs of expected counts of the inpatient utilization frequency is expected to increase by 1.213. These findings are consistent with Lin's findings [13]. These facts indicate that smoking greatly affects personal health. In addition, the WHO indicates that smoking jeopardizes 
TABLE 5: Estimation result of addictive factors on inpatient services utilization.

(a) Likelihood of inpatient services $(N=13,645)$

\begin{tabular}{lcccc}
\hline & \multicolumn{2}{c}{ Model 1 $^{\mathrm{a}}$} & & Model 2 $^{\mathrm{b}}$ \\
& Odds ratio & Standard error & Odds ratio & Standard error \\
\hline $\mathrm{DD}$ & $1.711^{* *}$ & 0.316 & $1.870^{* *}$ & 0.360 \\
$\mathrm{SM}$ & $1.860^{* * *}$ & 0.305 & $1.722^{* *}$ & 0.302 \\
$\mathrm{CBN}$ & $1.296^{+}$ & 0.190 & 1.194 & 0.189 \\
Two-factor & 1.278 & 0.281 & 1.250 & 0.287 \\
No addictive & \multicolumn{2}{c}{ Reference category } \\
factors & \multicolumn{2}{c}{ Reference category } \\
\hline
\end{tabular}

(b) Frequency of inpatient visits $(N=873)$.

\begin{tabular}{lcccc}
\hline & & & & Model 2 $^{\mathrm{b}}$ \\
& Coefficient & Sodel 1 & Coefficient & Standard error \\
\hline DD & -0.147 & 0.403 & -0.104 & 0.447 \\
SM & $1.318^{* * *}$ & 0.313 & $1.213^{* * *}$ & 0.356 \\
CBN & -0.182 & 0.326 & -0.341 & 0.387 \\
Two-factor & 0.195 & 0.459 & 0.149 & 0.506 \\
No & & & reference category \\
addictive & reference category \\
factors & & & \\
\hline
\end{tabular}

DD: deep drunk; SM: smoking cigarettes; CBN: chewing betel nut.

*** $P<0.001,{ }^{*} * P<0.01,{ }^{*} P<0.05,{ }^{+} P<0.1$

${ }^{a}$ Unadjusted model.

${ }^{\mathrm{b}}$ Fully-adjusted model controlling for socio-demographic, health status, and geographical factors.

almost each organ within the body and is one of main risk factors for contracting cancer. For example, $85 \%$ deaths from lung cancer are due to smoking and nearly one-fifth of deaths from cancer are attributed to lung cancer in Taiwan [45].

The probability and the frequency for the people in the CBN group (chewing betel nut at least 1-2 days each week and having no other addictive factors) of using outpatient services are lower than those for the people in the base group. Similar to the case of the DD group, this finding may imply that the people in the CBN group overlook personal health. Although the inpatient frequency of the CBN group is not significantly higher than that of the base group, about $60 \%$ of the patients with oral cancer have a habit of chewing betel nut in Taiwan. Oral cancer is one of the main sources of cancer deaths in Taiwan, and chewing betel nut is the major cause of oral cancer. Chewing betel nut is popular in Taiwan because the weather is suitable for betel nut growing and because the profit from betel nut businesses is high $[36,37]$. In addition, the statistics show that there is a growing trend towards chewing betel nut and a downward trend in the age of starting chewing betel nut $[36,37]$. Thus, a policy to dissuade people from chewing betel nut is desired.

We find some evidence that the degree of self-awareness of health decreases with the degree of addictive behaviorthe probability and frequency of using outpatient services are lower or insignificant for the people with two addictive factors. Compared with the people without any unhealthy behavior, the probability to visit a doctor of the people in the DD + CBN group is $50 \%$ of that of the people in the base group in Table 4(a), Model 2. Similar implication is also from the frequency analysis in Table 4(b). The people in the $\mathrm{DD}+\mathrm{CBN}$ group have fewer doctor visits than the people without any unhealthy behavior once they use outpatient services.

Although we find some evidence of impact of addictive behavior on health service utilizations, some research limitations should be mentioned. The negative effect from drinking, smoking, and chewing betel nut may take time to appear. In addition, Pohlmeier and Ulrich [46] point out that a limitation of the hurdle model, the measure of repeat visits to the doctor, relates to a single spell of illness. However, owing to data limitations, the questionnaire provides only the information regarding smoking, drinking, and chewing betel nut behaviors but not the information about previous addictive behaviors. Moreover, the dataset was linked by the 2005 NHIS and the 2005 NHIRD so that it only provides information in 2005. Thus, we are unable to analyze the effect of these addictive factors in the long term. In general, once a person becomes addicted to these unhealthy behaviors, it is difficult to quit the habits. In this study, we define the addictive behaviors as getting drunk at least once a week, smoking at least 20 cigarettes every day, and chewing betel nut at least 1-2 days a week. Although only one year of data is being used, the results of the study still give us the information about the impact of addictive behaviors on the medical care utilization.

Another research limitation of this study is that the number of observations with addictive behavior is relatively small, 
especially for the analysis of inpatient services. Although the NHIRD has complete medical records for each person under national health insurance, it lacks personal socio-economic variables. The NHIS contains valuable socio-economic information but no information regarding medical utilization. From the 24,726 complete observations, there are 18,538 respondents who are willing to provide their information for research. After we link these two datasets through personal ID numbers, only 13,651 observations provide complete information and only 873 of them include inpatient records. Moreover, there are only 6 observations that have all three addictive factors and none of them used inpatient services in 2005, which leads to estimation difficulties. Therefore, we use only 13,645 observations and analyze the addictive behaviors by grouping them into one addictive factor or two addictive factor groups. The readers should be cautons with the results from inpatient analysis (Table 5) since the sample with addictive behavior is relatively small in the inpatient dataset.

In spite of these limitations, our study contributes to the literature in that we investigate the effect of different degrees of addiction on the utilization of both outpatient and inpatient services. Our empirical results suggest that appropriate drinking, no smoking, and no chewing betel nut can improve national health and thus alleviate national health expenditure. The government can reach these goals by promotion and education to increase public awareness of personal health.

\section{Acknowledgments}

The authors are grateful to the anonymous referees and the editor for providing them with many constructive suggestions. The authors would also like to thank the 2005 National Health Interview Survey Original Database provided by the Bureau of Health Promotion, Department of Health and National Health Research Institutes in Taiwan.

\section{Endnotes}

1. According to the survey statistics compiled by the Institution of Occupational Safety and Health of Taiwan in 1999, the prevalence rates of smoking, of drinking, and of betel nut chewing for male labors were $47.5 \%$, $31.4 \%$, and $10.4 \%$, respectively. For those who regularly consumed these goods, the average quantities per male were 13.6 cigarettes, $321 \mathrm{~mL}$ of alcohol, and 9.7 betel nuts per day. Unfortunately, we do not find the data regarding the personal expenditure on these goods. However, since the average prices of cigarettes per pack and betel nut per pack were both around NTD 50, we can make estimation of personal expenditures on them. The annual expenditure on cigarettes for a man who smoked was about NTD 12410 . The annual expenditure on betel nut for a man who chewed it was about NTD17 703. The latter number was about $4 \%$ of GDP per capita of Taiwan in 1999 . We do not make estimation of the expenditure on alcohol consumption because the price range of alcohol is widespread depending on the kinds of alcohol and the places of alcohol consumption. More statistics about prevalence rates of unhealthy behaviors may be found at website of the Institution of Occupational Safety and Health of Taiwan. http://www.iosh.gov.tw/Publish.aspx? cnid=16\&P=136.

2. It would be interesting to examine the impact of these addictive behaviors on health expenditure in the second-part analysis. We did try to use medical expenditure as the explained variable in the second part. However, we failed to obtain convergent result for expenditure analysis so we gave up the direct expenditure analysis in this study.

\section{References}

[1] U. G. Gerdtham, J. Sogaard, F. Andersson, and B. Jonsson, "An econometric analysis of health care expenditure: a crosssection study of the OECD countries," Journal of Health Economics, vol. 11, no. 1, pp. 63-84, 1992.

[2] T. E. Getzen, "Health care is an individual necessity and a national luxury: applying multilevel decision models to the analysis of health care expenditures," Journal of Health Economics, vol. 19, no. 2, pp. 259-270, 2000.

[3] P. Hansen and A. King, "Health care expenditure and GDP: panel data unit root test results-comment," Journal of Health Economics, vol. 17, no. 3, pp. 377-381, 1998.

[4] R. E. Leu, "The public-private mix and international health care costs," in Public and Private Health Services: Complementaries and Conflicts, A. J. Culyer and B. Jonsson, Eds., Basic Blackwell, Oxford, UK, 1986.

[5] E. Kleiman, "The determinants of natinal outlay on health," in The Economics of Health and Medical Care, M. Perlman, Ed., Macmillan, London, UK, 1974.

[6] J. P. Newhouse, "Medical-care expenditure: a cross-national survey," Journal of Human Resources, vol. 12, no. 1, pp. 115125, 1977.

[7] T. E. Getzen, "Macro forecasting of national health expenditures," in Advances in Health Economics and Health Services Research, R. M. Scheffler and L. F. Rossiter, Eds., JAI Press, Greenwich, Conn, USA, 1990.

[8] T. Hitiris and J. Posnett, "The determinants and effects of health expenditure in developed countries," Journal of Health Economics, vol. 11, no. 2, pp. 173-181, 1992.

[9] S. K. McCoskey and T. M. Selden, "Health care expenditures and GDP: panel data unit root test results," Journal of Health Economics, vol. 17, no. 3, pp. 369-376, 1998.

[10] N. R. V. Murthy and V. Ukpolo, "Aggregate health care expenditure in the United States: evidence from coingegration tests," Applied Economics, vol. 26, pp. 797-802, 1994.

[11] J. P. Newhouse, "Medical care costs: how much welfare loss?" The Journal of Economic Perspectives, vol. 6, no. 3, pp. 3-21, 1992.

[12] J. Cawley, "An economic framework for understanding physical activity and eating behaviors," American Journal of Preventive Medicine, vol. 27, no. 3, pp. 117-125, 2004.

[13] T. F. Lin, "Modifiable health risk factors and medical expenditures-the case of Taiwan," Social Science and Medicine, vol. 67, no. 11, pp. 1727-1736, 2008.

[14] C. Pisinger, U. Toft, M. Aadahl, C. Glümer, and T. Jørgensen, "The relationship between lifestyle and self-reported health in 
a general population. The Inter99 study," Preventive Medicine, vol. 49, no. 5, pp. 418-423, 2009.

[15] K. E. Thorpe, "The rise in health care spending and what to do about it: disease prevention/health promotion approaches are key to slowing the rise in health care spending," Health Affairs, vol. 24, no. 6, pp. 1436-1445, 2005.

[16] T. A. Hodgson, "Cigarette smoking and lifetime medical expenditures," The Milbank Quarterly, vol. 70, no. 1, pp. 81$125,1992$.

[17] E. Johnson, F. Dominici, M. Griswold, and S. L. Zeger, "Disease cases and their medical costs attributable to smoking: an analysis of the national medical expenditure survey," Journal of Econometrics, vol. 112, no. 1, pp. 135-151, 2003.

[18] V. P. Miller, C. Ernst, and F. Collin, "Smoking-attributable medical care costs in the USA," Social Science and Medicine, vol. 48, no. 3, pp. 375-391, 1999.

[19] M. C. Yang, C. Y. Fann, C. P. Wen, and T. Y. Cheng, "Smoking attributable medical expenditures, years of potential life lost, and the cost of premature death in Taiwan," Tobacco Control, vol. 14, no. 1, pp. i62-i70, 2005.

[20] H. J. Chang, C. H. Hsieh, T. P. Chiang, and S. C. Huang, "Evaluation of the policy of catastrophic illness of national health insurance," Socioeconomic Law and Institution Review, vol. 33, pp. 27-74, 2004.

[21] C. H. Denny, M. K. Serdula, D. Holtzman, and D. E. Nelson, "Physician advice about smoking and drinking: are U.S. adults being informed?" American Journal of Preventive Medicine, vol. 24, no. 1, pp. 71-74, 2003.

[22] B. G. Druss, S. C. Marcus, M. Olfson, T. Tanielian, L. Elinson, and H. A. Pincus, "Comparing the national economic burden of five chronic conditions," Health Affairs, vol. 20, no. 6, pp. 233-241, 2001.

[23] U. Kiiskinen, E. Vartiainen, P. Puska, and M. Pekurinen, "Smoking-related costs among 25 to 59 year-old males in a 19year individual follow-up," European Journal of Public Health, vol. 12, no. 2, pp. 145-151, 2002.

[24] G. F. Riley, "Long-term trends in the concentration of medicare spending," Health Affairs, vol. 26, no. 3, pp. 808-816, 2007.

[25] K. E. Thorpe, C. S. Florence, and P. Joski, "Which medical conditions account for the rise in health care spending?" Health Affairs, vol. 23, no. 2, pp. W437-W445, 2004.

[26] R. Doll, R. Peto, J. Boreham, and I. Sutherland, "Mortality in relation to smoking: 50 Years' observations on male British doctors," British Medical Journal, vol. 328, no. 7455, pp. 1519$1528,2004$.

[27] M. Ezzati and A. D. Lopez, "Estimates of global mortality attributable to smoking in 2000," Lancet, vol. 362, no. 9387, pp. 847-852, 2003.

[28] C. R. Hsieh, "Health risk and the decision to quit smoking," Applied Economics, vol. 30, no. 6, pp. 795-804, 1998.

[29] K. Hayashida, Y. Imanaka, G. Murakami et al., "Difference in lifetime medical expenditures between male smokers and nonsmokers," Health Policy, vol. 94, no. 1, pp. 84-89, 2010.

[30] R. E. Leu and T. Schaub, "Does smoking increase medical care expenditure?” Social Science and Medicine, vol. 17, no. 23, pp. 1907-1914, 1983.

[31] J. J. Stoddard and B. Gray, "Maternal smoking and medical expenditures for childhood respiratory illness," American Journal of Public Health, vol. 87, no. 2, pp. 205-209, 1997.

[32] K. M. Fillmore, J. M. Golding, K. L. Graves et al., "Alcohol consumption and mortality. I. Characteristics of drinking groups," Addiction, vol. 93, no. 2, pp. 183-203, 1998.
[33] D. Petrie, C. Doran, A. Shakeshaft, and R. Sanson-Fisher, "The relationship between alcohol consumption and self-reported health status using the EQ5D: evidence from rural Australia," Social Science and Medicine, vol. 67, no. 11, pp. 1717-1726, 2008.

[34] A. C. Salisbury, J. A. House, M. W. Conard, H. M. Krumholz, and J. A. Spertus, "Low-to-moderate alcohol intake and health status in heart failure patients," Journal of Cardiac Failure, vol. 11, no. 5, pp. 323-328, 2005.

[35] W. Sun, C. M. Schooling, W. M. Chan, K. S. Ho, T. H. Lam, and G. M. Leung, "Moderate alcohol use, health status, and mortality in a prospective Chinese elderly cohort," Annals of Epidemiology, vol. 19, no. 6, pp. 396-403, 2009.

[36] S. C. Wang, C. C. Tsai, S. T. Huang, and Y. J. Hong, "Betel nut chewing: the prevalence and the intergenerational effect of parental behavior on adolescent students," Journal of Adolescent Health, vol. 34, no. 3, pp. 244-249, 2004.

[37] S. C. Wang, C. C. Tsai, S. T. Huang, and Y. J. Hong, "Betel nut chewing and related factors in adolescent students in Taiwan," Public Health, vol. 117, no. 5, pp. 339-345, 2003.

[38] Taiwan Tobacco Control Annual Report, Departmen of Health, Bureau of Health Promotion, Taipei, Taiwan, 2009, http://www.bhp.doh.gov.tw/manual/manual_006.html.

[39] Executive Yuan, Taipei, Taiwan: Department of Health; 2009, Taipei, Taiwan, http://www.doh.gov.tw/.

[40] W. Pohlmeier and V. Ulrich, "An econometric model of the two-part decisionmaking process in the demand for health care," The Journal of Human Resources, vol. 30, pp. 339-361, 1995.

[41] A. C. Cameron and P. K. Trivedi, Models of Count Data. Microeconometrics: Methods and Applications, Cambridge University Press, New York, NY, USA, 2005.

[42] A. M. Jones, "Health econometrics," in Handbook of Health Economics, A. J. Culyer and J. P. Newhouse, Eds., Elsevier, Amsterdam, The, Netherlands, 2000.

[43] U. Häkkinen, G. Rosenqvist, and S. Aro, "Economic depression and the use of physician services in Finland," Health Economics, vol. 5, no. 5, pp. 421-434, 1996.

[44] U. G. Gerdtham, "Equity in health care utilization: further tests based on hurdle models and Swedish micro data," Health Economics, vol. 6, no. 3, pp. 303-319, 1997.

[45] Taiwan Cancer Registry, Executive Yuan, Department of Executive Yuan, Taipei, Taiwan. Department of Health, Taipei, Taiwan, 2009, http://crs.cph.ntu.edu.tw/crs_c/index_c.htm.

[46] W. Pohlmeier and V. Ulrich, "An econometric model of the two-part decision making process in the demand for health care," The Journal of Human Resources, vol. 30, pp. 339-361, 1995. 


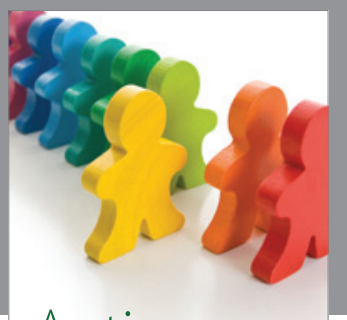

Autism

Research and Treatment
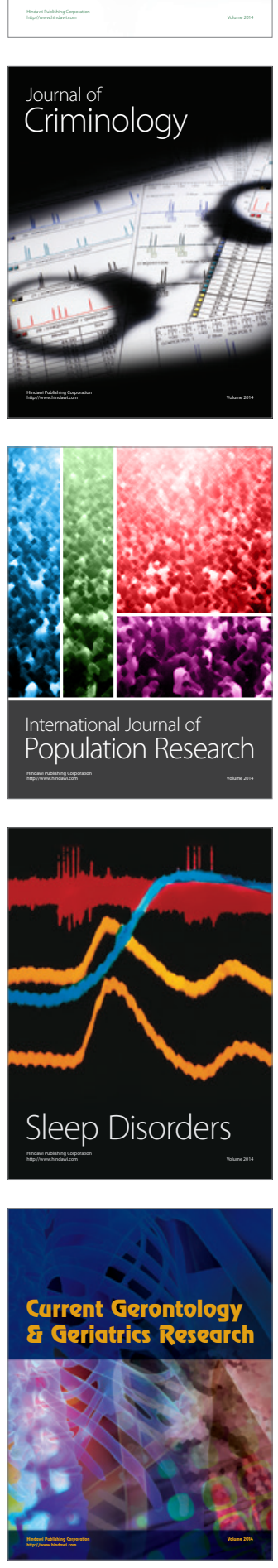
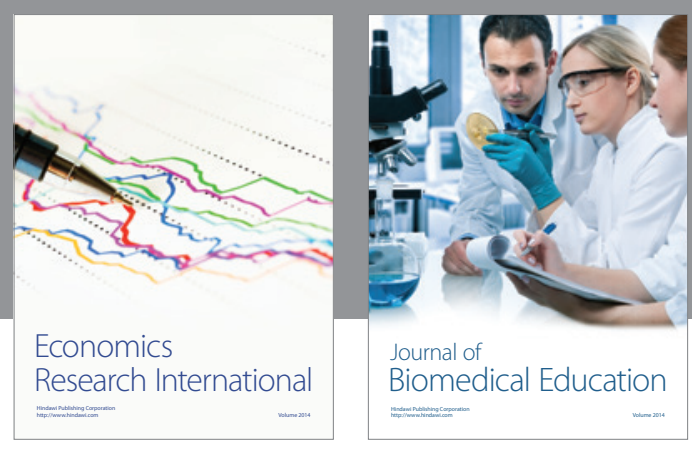

Journal of

Biomedical Education

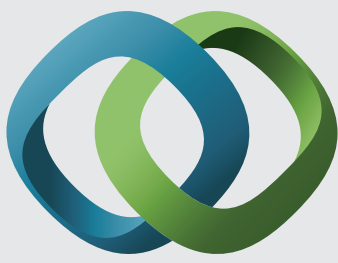

\section{Hindawi}

Submit your manuscripts at

http://www.hindawi.com
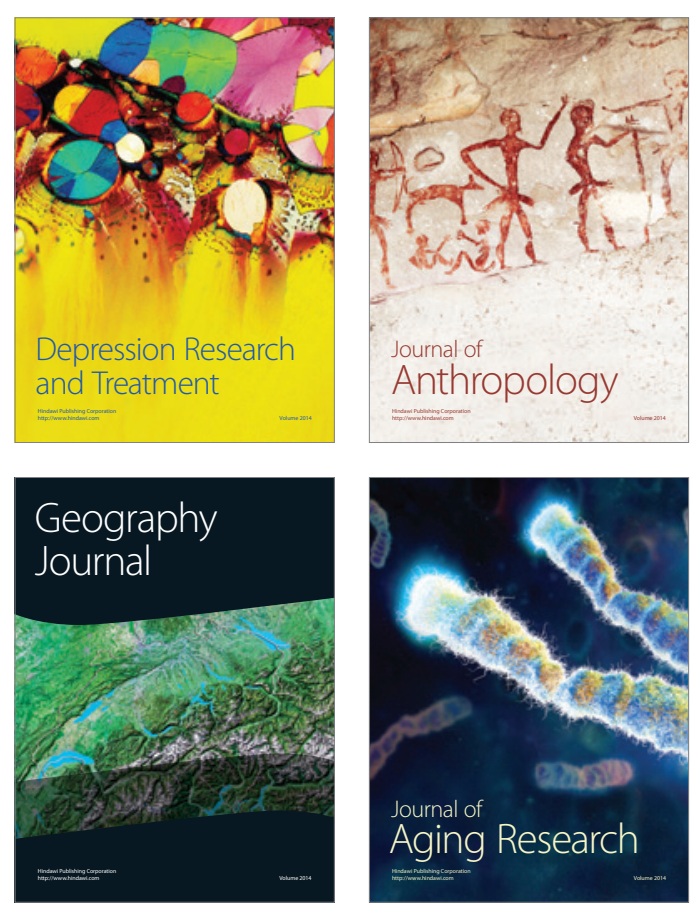

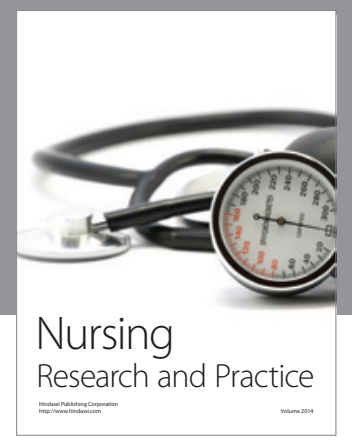

Nursing

Research and Practice

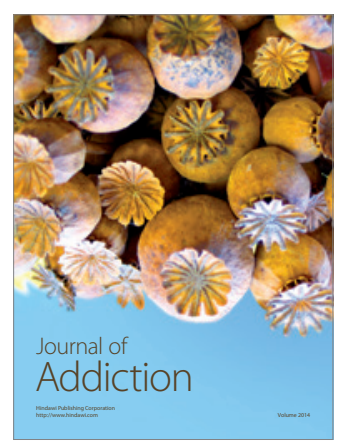

Child Development

Research

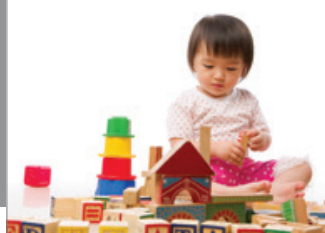

迥
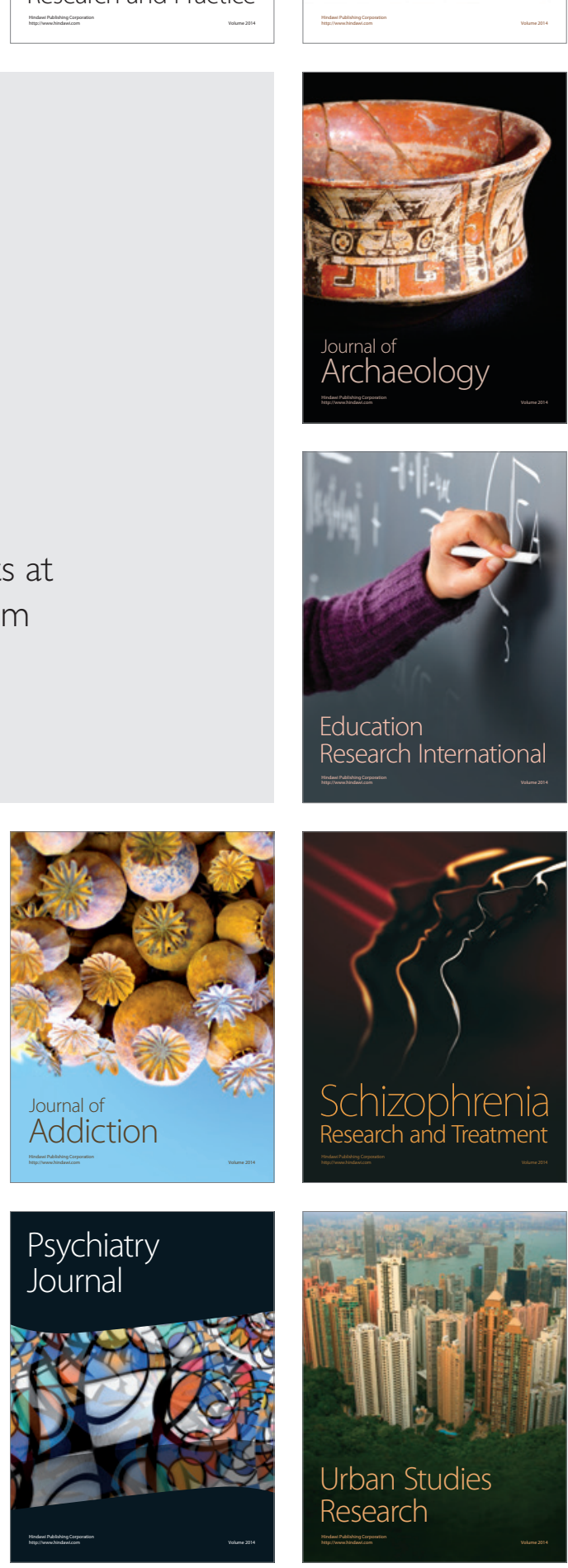